\title{
Modulation of Osteonectin and Osteopontin Expression during Fracture Healing of Mouse Bone Tissue
}

\author{
Hideyoshi Kashimoto ${ }^{1,2}$, Riko Kitazawa ${ }^{1}$, Sakan Maeda ${ }^{1}$, Kosaku Mizuno ${ }^{2}$ and \\ Sohei Kitazawa ${ }^{1}$ \\ ${ }^{1}$ Second Department of Pathology, ${ }^{2}$ Department of Orthopaedic Surgery, Kobe University School of Medicine, 7-5-1, \\ Kusunoki-cho, Chuo-ku, Kobe 650-0017
}

Received for publication November 19, 1998 and in revised form December 15, 1998

\begin{abstract}
We investigated the expression of osteonectin and osteopontin during fracture healing of mouse tibiae by in situ hybridization (ISH) and the effects of fibrin(ogen) on the expression of bone matrix proteins by Northern blot analysis. Twelve-week-old male BALB/c mice were operated on to make a closed fracture on the proximal tibiae. On days 2 , 4,7 and 14 after the operation, the fractured bones were excised, fixed with $4 \%$ paraformaldehyde (PFA) and decalcified with 20\% EDTA to prepare $5-\mu \mathrm{m}$ sections. Digoxigenin (DIG) labeled single-stranded DNA probes generated by uni-directional polymerase chain reaction (PCR) were used for ISH. Immunohistochemistry revealed fibrin(ogen) at the site of fracture hematoma 2-4 days after fracture and subsequent accumulation

of mesenchymal cells. On days 4-14 after the fracture, osteonectin signals were predominantly expressed in proliferating chondrocytes at the endochondral ossification site and in osteoblasts of the marginal woven bone. Osteopontin was expressed on osteoblasts lining the surface of the marginal woven bone at the mid-late phase of fracture healing. In vitro, Northern blot analysis showed that treatment of the mesenchymal cells, С3H10T1/2, with fibrin(ogen) enhanced the steady-state level of osteonectin and osteopontin gene expression. These data suggested that fibrin(ogen) in the hematoma may be important for inducing bone matrix genes in immature mesenchymal cells at the early phase of fracture repair.
\end{abstract}

Key words: Bone matrix protein, In situ hybridization, Polymerase chain reaction, Fracture healing

\section{Introduction}

Fracture healing is a complex sequence of events involving hematoma formation, recruitment of inflammatory and mesenchymal cells, induction of cartilaginous and bony callus and remodeling of woven bone tissue with the reappearance of bone marrow spaces $[9,16]$. To promote the process of fracture healing, local as well as systemic factors are prerequisites to regulating the proliferation and differentiation of the mesenchymal cell lineage. The involvement of bone morphogenetic proteins (BMPs) in fracture repair has been postulated $[2,18]$, and their expression has been histologically analyzed by in situ hybridization studies [12,7]. Little however, is known about the initial events which trigger the recruitment of

Correspondence to: Dr. Sohei Kitazawa, Second Department of Pathology, Kobe University School of Medicine, 7-5-1, Kusunokicho, Chuo-ku, Kobe 650-0017, Japan. mesenchymal cells at the fractured site.

During the process of wound healing, fibrin(ogen) initially promotes the proliferation, differentiation and migration of mesenchymal cells [13] and induction of blood vessels [3]. The fibrin clot in hematoma also offers frames to which fibroblasts bind at RGD sites through $\alpha \mathrm{v} \beta 3$ integrin [17]. Indeed, fibrin glue (sealant) has been applied as a surgical aid for facilitating wound closure and creating an optimal setting for wound healing [1].

In this study, we investigated the expression and localization of bone matrix proteins, osteoblastic differentiation markers, in relation to the fibrin(ogen) clot by in situ hybridization using single-stranded antisense DNA probes generated by uni-directional polymerase chain reaction (PCR) $[7,8]$. We further analyzed the in vitro effects of fibrin(ogen) on the steady-state level of osteonectin, osteopontin, alkaline phosphatase and biglycan gene expression in $\mathrm{C} 3 \mathrm{H} 10 \mathrm{~T} 1 / 2$, an immature mesenchymal cell line. 


\section{Materials and Methods}

\section{Animal experiment and tissue preparation}

Twelve-week-old male BALB/c mice (Charles River Japan, Yokohama, Japan) were anesthetized with Sodium Penthobarbital $(60 \mu \mathrm{g} / \mathrm{gBW})$ and operated on to make a closed transverse fracture on one third of the proximal tibia with the three-point bending device. On days 2, 4, 7 and 14 after the operation, the fractured mouse tibiae were excised and fixed with $4 \%$ paraformaldehyde (PFA) at $4{ }^{\circ} \mathrm{C}$ for 2 days. Bone specimens were decalcified with $20 \%$ EDTA for 3 days then embedded in paraffin. Longitudinal 5- $\mu \mathrm{m}$ thick sections were cut and mounted on glass slides coated with 2\% 3-aminopropyltriethoxy silan (SIGMA, St. Louis, MO, USA) in acetone. Representative sections for each experiment were stained with hematoxylin and eosin (HE) to observe the histological changes during fracture healing. All animal experiments were conducted according to the "Guidelines for Animal Experimentation at Kobe University School of Medicine."

\section{Immunohistochemistry}

To investigate the localization of fibrin(ogen) in the mouse tibia after the fracture, anti-340 kD fibrin(ogen) monoclonal antibody (Cosmo Bio, Tokyo, Japan) was used. The sections were dewaxed and rehydrated, then treated with $3 \%$ hydrogen peroxide in $100 \%$ methanol to block the endogenous peroxidase activity. After treatment with the blocking solution (DAKO Corp., Carpenteria, CA), the sections were incubated with the primary antibody for fibrin(ogen) at a final concentration of $5 \mu \mathrm{g} / \mathrm{ml}$ in phosphate buffer saline (PBS) for $2 \mathrm{hr}$ at room temperature. The avidin-biotin-peroxidase complex (ABC) method was used with a commercial kit (DAKO Corp., Carpenteria, CA). Final development with the Nickel-Cobalt enhancement method [21] was carried out with 3, 3-diaminobenzidine (DAB) containing 0.03\% hydrogen peroxide in PBS. Samples were observed under a light microscope without counterstaining.

\section{Reverse transcriptase (RT)-PCR and probe preparation}

Total RNA was extracted from the mouse kidney with the commercially available RNA extraction system, RNAzol, according to the manufacturer's instructions (TEL-TEST, INC., Friendswood, TX, USA), and used as a template for RT-PCR. A $320 \mathrm{bp}$ cDNA fragment from the coding region of mouse osteopontin (OP) and a $280 \mathrm{bp}$ cDNA from osteonectin $(\mathrm{ON})$ were amplified by RT-PCR with rTth reverse transcriptase (Perkin-Elmer Cetus, Norwalk, CT, USA) using the following pairs of oligonucleotide primers:

primer OP (sense); 5'-GCCTGACCCATCTCAGAAGCAGAAT-3'

primer OP (antisense); 5'-TAAGCCAAGCTATCACCTCGGCCGT-3'

primer ON (sense); 5'-AGCGTCAAGCCAAACACAAACAGCG-3' primer ON (antisense); 5'-CATCTAGGTACAACATGGAGATTGC-3'

An antisense primer-primed reverse transcription was done at $60^{\circ} \mathrm{C}$ for $60 \mathrm{~min}$, followed by both sense and antisense primer-primed PCR amplification to obtain each DNA fragment. The cycling conditions for PCR were denaturation at $94^{\circ} \mathrm{C}$ for $15 \mathrm{sec}$, annealing at $67^{\circ} \mathrm{C}$ for 15 $\mathrm{sec}$ and elongation at $72^{\circ} \mathrm{C}$ for $30 \mathrm{sec}$, for a total of 35 cycles. Amplified PCR products were loaded onto 3\% agarose gel, and DNA bands of the predicted size were cut and purified with glass powder (Takara, Tokyo, Japan). To confirm that the RT-PCR products were derived from desired CDNA, the purified PCR products were sequenced by the dideoxy termination method and analyzed with an ABI PRISM-310 automated sequencer. To prepare the digoxigenin (DIG)-labeled single-stranded antisense DNA probe, the purified PCR product was subjected to unidirectional PCR with the antisense primer alone in the presence of DIG-dUTP (DIG-dUTP, digoxigenin DNA labeling mixture, Boehringer Mannheim, Mannheim, Germany) with the same PCR parameters for a total of 40 cycles. The efficiency of the probe generation was monitored by the electrophoresis of both the primary (double-stranded DNA) and secondary PCR products (single-stranded DIG-labeled DNA). The DIG-labeled single-stranded antisense DNA was purified with Quickspin $^{\mathrm{TM}}$ Column Sephadex-G50, Fine (Boehringer Mannheim, Mannheim, Germany) at a speed of $500 \mathrm{G}$. Each probe was sensitive enough to detect as little as $2 \mathrm{pg}$ of individual DNA when hybridized with the denatured unlabeled cDNAs spotted onto the nylon filter; no cross reactivity was found as previously described $[7,8]$. For negative controls, DIG-labeled sense probes were generated with sense primer-primed uni-directional PCR.

\section{In situ hybridization (ISH)}

After dewaxing in xylene and rehydrating through a series of graded ethanol, tissue sections were treated with $2-5 \mu \mathrm{g} / \mathrm{ml}$ proteinase K (SIGMA, St. Louis, MO, USA) for $10 \mathrm{~min}$, refixed with $4 \%$ PFA, immersed in $0.1 \mathrm{M}$ triethanolamine $(\mathrm{pH} \mathrm{8.0)}$ for $10 \mathrm{~min}$ and in $0.1 \mathrm{M}$ triethanolamine containing $0.25 \%$ acetic acid for $15 \mathrm{~min}$, and washed in $0.1 \mathrm{M}$ phosphate buffer ( $\mathrm{pH}$ 7.4). The samples were then incubated in a hybridization medium [10 mM Tris- $\mathrm{HCl}$ (pH 7.3), $1 \mathrm{mM}$ EDTA, $600 \mathrm{mM} \mathrm{NaCl}$, $0.25 \%$ sodium dodecyl sulfate, $1 \times$ Denhardt's Medium, $50 \%$ (v/v) deionized formamide/ $1 \mathrm{ng} / \mathrm{ml}$ of probe DNA, $10 \%$ dextran sulfate] at $50^{\circ} \mathrm{C}$ in a moist chamber for $16 \mathrm{hr}$. Negative controls were prepared with either a DIG-labeled sense DNA or RNase predigestion. After hybridization, the slides were washed with $50 \%$ deionized formamide/ $2 \times$ SSC to remove the superfluous probe, and washed further with $2 \times \mathrm{SSC}$ and $0.2 \times \mathrm{SSC}$. To visualize the hybridized probe, the slides were incubated with alkaline phosphatase (ALP)-conjugated anti-DIG antibody (Boehringer Mannheim, Mannheim, Germany) for $60 \mathrm{~min}$ after blocking with $1.5 \%$ non-fat dry milk in PBS for 
30 min. The specimens were then washed twice with 100 $\mathrm{mM}$ Tris- $\mathrm{HCl}(\mathrm{pH} 7.5$ ) containing $150 \mathrm{mM} \mathrm{NaCl}$ for 20 min each time, and immersed briefly in $100 \mathrm{mM}$ Tris- $\mathrm{HCl}$ (pH 9.5) containing $100 \mathrm{mM} \mathrm{NaCl}$ and $50 \mathrm{mM} \mathrm{MgCl}_{2}$. The colorimetric reaction was done with nitro-blue tetrazolium salt and bromo-4-chloro-3-indolyl phosphate solution (Boehringer Mannheim, Mannheim, Germany) in the dark for $6 \mathrm{hr}$, then stopped with $10 \mathrm{mM}$ Tris- $\mathrm{HCl}(\mathrm{pH}$ 8.0) containing $1 \mathrm{mM}$ EDTA. Slides were mounted with CRYSTAL/MOUNT ${ }^{\mathrm{TM}}$ (Biomedica, Foster City, CA, USA) and analyzed under a light microscope without counterstaining.

\section{Cell culture}

Mouse mesenchymal cells, C3H10T1/2 (RIKEN Cell Bank, Wako, Japan), were cultured with BME medium (SIGMA, St. Louis, MO, USA) supplemented with 10\% Fetal Bovine Serum (ICN Biomedicals Inc., Aurora, $\mathrm{OH}$, USA). The C3H10T1/2 cells were then subcultured $(5 \times$ $10^{5} / \mathrm{cm}^{2}$ ) in 24-well multiwell plates or $60 \mathrm{~mm}$ culture dishes in the serum-free condition. Cells were treated with fibrin(ogen) (Wako Pure Chemical, Osaka, Japan) or $1,25(\mathrm{OH})_{2}$ Vitamin $\mathrm{D}_{3}$ (Duphar, Netherlands), or both. To assess the effects of fibrin(ogen) and Vitamin $\mathrm{D}_{3}$ on cell proliferation, the cell number was analyzed with photoabsorbance $(420 \mathrm{~nm})$ by the WST-1 assay system, Cell Counting Kit, according to the manufacturer's instructions (Dojin Chemical, Kumamoto, Japan). Three sets of independent experiments in duplicate were carried out, and effects of fibrin(ogen) were analyzed by one-way analysis of variance and Fisher protected LSD test.

\section{Northern blot hybridization}

To assess the effect of serum proteins on the steadystate expression of OP and ON, four sets of the Northern blot analyses were carried out. Total RNA was extracted and purified by RNAzol ${ }^{\mathrm{TM}}$ (Tel-Test, Inc, TX, USA) from C3H10T1/2 cells treated with fibrin(ogen) and/or Vitamin $\mathrm{D}_{3}$ for $48 \mathrm{hr}$. A quantity of $7.5 \mu \mathrm{g}$ of each RNA was electrophoresed on a 1.2\% agarose gel and transferred onto the Hybond $\mathrm{N}+$ nylon membrane. We used the same probes as in ISH for OP and ON, and bovine cDNA for ALP and biglycan (a kind gift from Drs. M. F. Young and K. Ibaraki-O'Connor, NIH, Bethesda, MD, USA). The c-fos probe was purchased from Takara, Tokyo, Japan. Probes were labeled with $\alpha^{32} \mathrm{P}$-dCTP by the random labeling method. The membranes were hybridized at $60^{\circ} \mathrm{C}$ for $16 \mathrm{hr}$, and washed twice in $2 \times \mathrm{SSPE}$ at room temperature and in $0.1 \times \mathrm{SSPE}$ at $60^{\circ} \mathrm{C}$ and exposed to Kodak XOMAT film for 2 days at $-80^{\circ} \mathrm{C}$.

\section{Results}

Bone matrix proteins on fractured mouse tibiae were analyzed sequentially after the bone fracture. In the initial phase, 1-2 days after fracture, a hematoma consisting of blood clots and inflammatory cells appeared at the
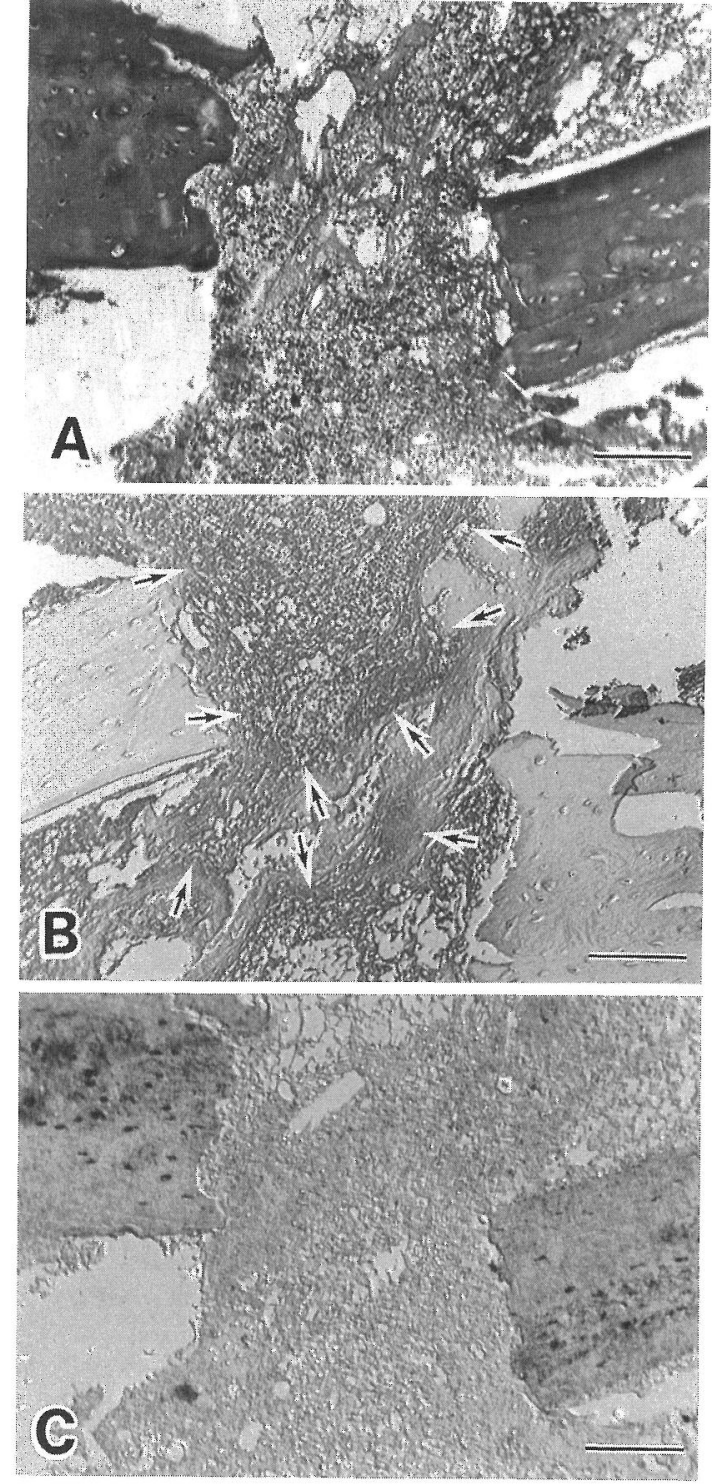

Fig. 1. Histological micrographs of mouse tibiae harvested 2 days after the fracture $(\times 100)$. A: H.E. staining. B: Immunohistochemistry for fibrin(ogen). C: In situ hybridization for mouse OP mRNA. Two days after fracture, inflammatory and mesenchymal cells accumulated close to the blood clot where immunoreactivity (arrows) for fibrin(ogen) was demonstrated (B). No signal for OP mRNA was detected in the hematoma lesion (C). Bars indicate $100 \mu \mathrm{m}$.

fracture site as shown in Fig. 1A. Immunoreactivity for fibrin(ogen) was demonstrated on the hematoma (Fig. 1B). Neither osteopontin (Fig. 1C) nor osteonectin signals (data not shown) were detected on the hematoma by in situ hybridization. Within a few days, mesenchymal cells migrated and proliferated adjacent to the fracture site, where remnants of blood clots were scarcely observed (Fig. 2A). As shown in Fig. 2B, mesenchymal cells at the periosteal site weakly expressed osteopontin mRNA as well as osteonectin (Fig. 2C) on day 4.

Seven days after the fracture, mesenchymal cells 

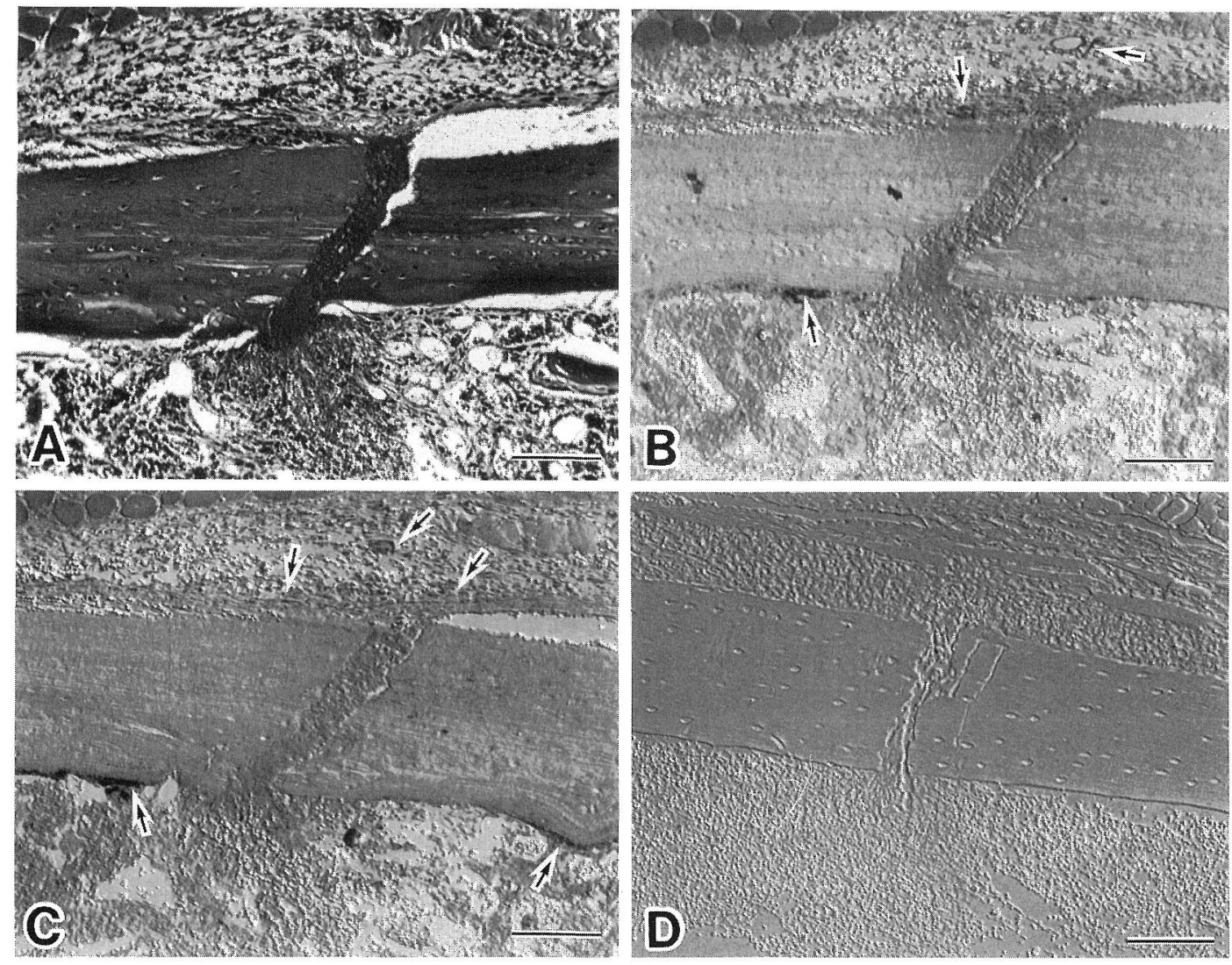

Fig. 2. Histological micrographs of mouse tibiae harvested 4 days after the fracture $(\times 100)$. A: H.E. staining. B: In situ hybridization for mouse OP. C: In situ hybridization for mouse ON. D: Hybridization with a sense probe for mouse ON. Mesenchymal cells accumulating at the periosteal site and endosteal osteoblasts sporadically expressed signals (arrows) for OP (B) and ON (C). No signal was detected in the specimen hybridized with the single-stranded sense DNA probe for ON (D). Bars indicate $100 \mu \mathrm{m}$.

differentiated into chondrocytes at the endochondral ossification site close to the gap in the fractured bone. Proliferating chondrocytes expressed moderate signals for osteopontin (Fig. 3B) and osteonectin (Fig. 3C). Hypertrophic chondrocytes strongly expressed the same signals. In the periosteal region beside the fracture site, mesenchymal cells directly differentiated into osteoblasts to form the woven bone tissue expressing transcripts both for osteopontin and osteonectin (data not shown). Fourteen days after the fracture, cartilaginous callus had almost wholly been replaced by the woven bone, where osteoblasts lining the trabecular bone surface strongly expressed osteopontin and osteonectin (Fig. 3C-E). Signals were detected neither in the specimens hybridized with sense probes (Fig. 2D) nor in those predigested with RNase (data not shown).

To evaluate the direct effect of fibrin(ogen) on the osteoblastic differentiation of mesenchymal cells, we investigated the expression of the genes of bone matrix proteins as markers for osteoblastic differentiation by Northern blot analysis. As shown in Fig. 4, fibrin(ogen) alone or with $1,25(\mathrm{OH})_{2}$ Vitamin $\mathrm{D}_{3}$ enhanced the steadystate expression of both osteonectin and osteopontin genes on the C3H10T1/2 mouse mesenchymal cell line. The relative optical densities to the control, standardized by the expression level of the G6PDH, are listed. On the other hand, although $1,25(\mathrm{OH})_{2}$ Vitamin $\mathrm{D}_{3}$ slightly enhanced the expression of biglycan and alkaline phosphatase genes, fibrin(ogen) alone did not promote C3H10T1/2 cells to express them (Fig. 5).

To assess the effect of fibrin(ogen) on mesenchymal cell proliferation, a number of $\mathrm{C} 3 \mathrm{H} 10 \mathrm{~T} 1 / 2$ cells treated with fibrin(ogen) were analyzed. As shown in Fig. 6, fibrin(ogen) treatment increased cell growth slightly but significantly; at the same time, it enhanced the steady-state expression of c-fos mRNA, a marker for cell proliferation of the osteoblastic lineage as revealed by Northern blot analysis. The relative optical densities to the control, standardized by the expression level of the G6PDH, are listed.

\section{Discussion}

We analyzed the sequential changes of bone matrix proteins as markers for osteoblastic differentiation in the process of fracture healing. To demonstrate the expression of each bone matrix protein, the ISH technique was selected as the response of gene expression can be detected 

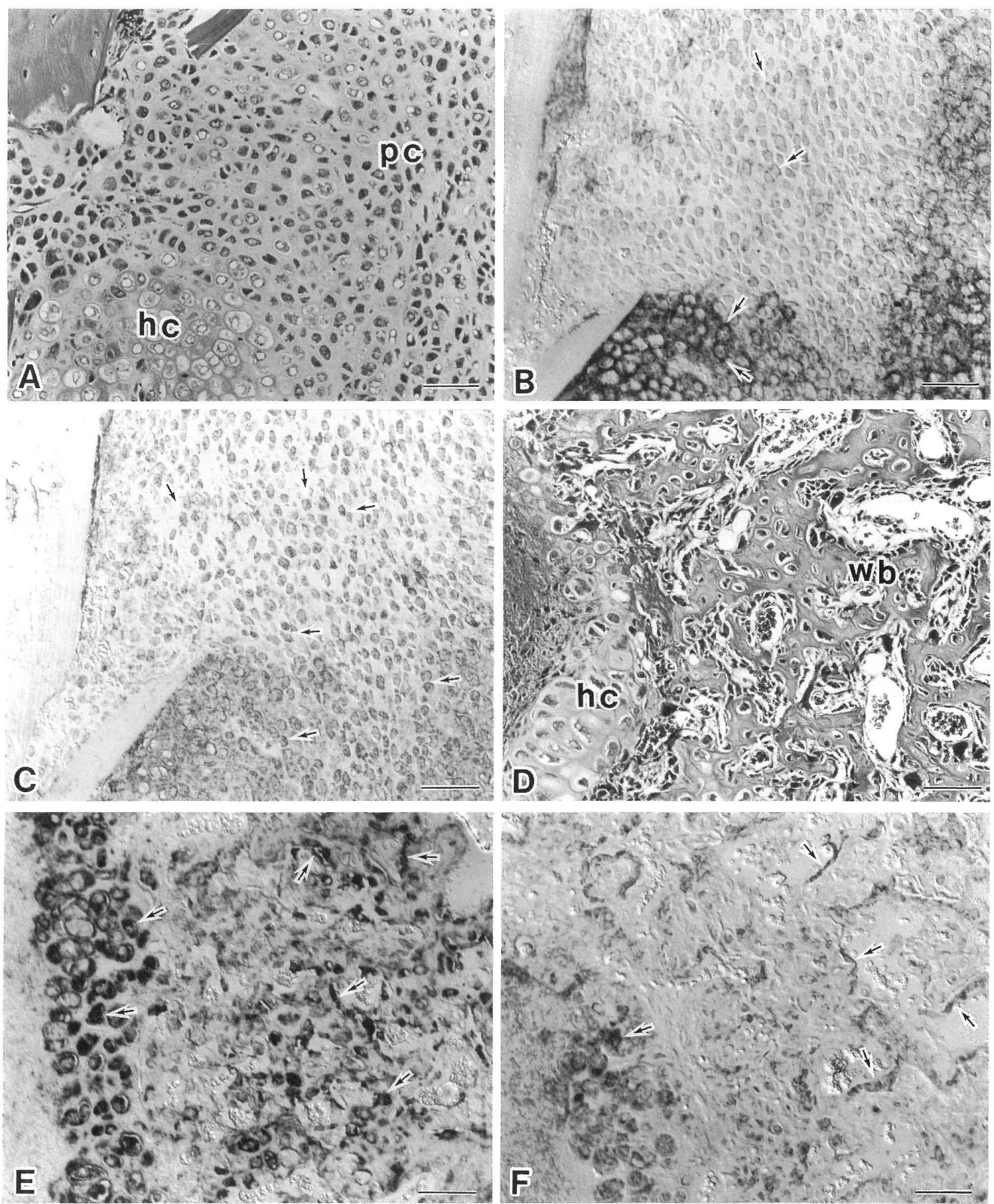

Fig. 3. Histological micrographs of mouse tibiae harvested 7 days $(\mathbf{A}, \mathbf{B}, \mathbf{C})$ and 14 days $(\mathbf{D}, \mathbf{E}, \mathbf{F})$ after the fracture $(\times 200)$. A, D: H.E. staining of mouse tibiae. B, E: In situ hybridization for mouse OP. C, F: In situ hybridization for mouse ON. Seven days after fracture mesenchymal cells differentiated into proliferating (pc) and hypertrophic chondrocytes (hc), expressing signals (arrows) for OP (B) and ON (C). Remnant cartilaginous callus (hypertrophic chondrocyte; hc) and woven bone tissue (wb) covered with osteoblasts expressing signals (arrows) for OP (E) and $\mathrm{ON}(\mathbf{F})$ were observed 14 days after the fracture. Bars indicate $50 \mu \mathrm{m}$. 


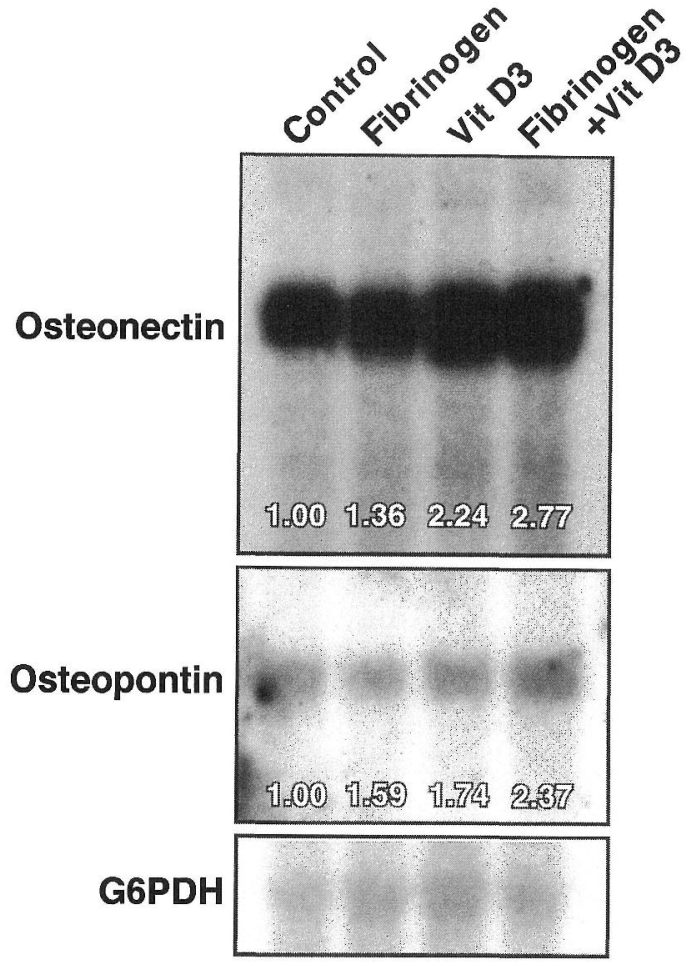

Fig. 4. Northern blot analysis for $O N$ and OP. Fibrin(ogen) alone or with Vitamin $\mathrm{D}_{3}$ enhanced the expression of osteonectin (ON) and osteopontin (OP) mRNA by $\mathrm{C} 3 \mathrm{H} 10 \mathrm{~T} / 1 / 2$ cells. The relative optical densities to the control, standardized by G6PDH, are listed.

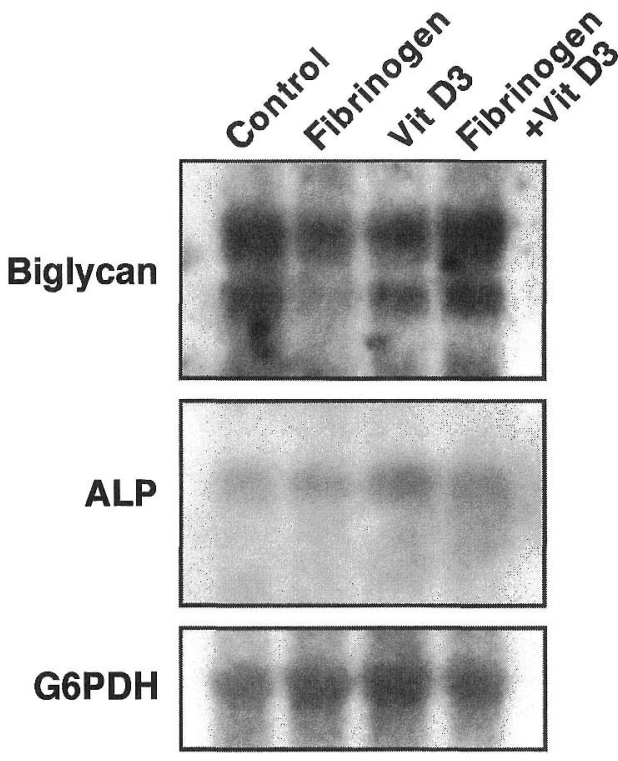

Fig. 5. Northern blot analysis for biglycan and alkaline phosphatase. Combined treatment of fibrin(ogen) and Vitamin $D_{3}$ enhanced the steady-state expression of biglycan mRNA, although fibrin(ogen) alone did not affect it. Alkaline phosphatase expression was also not affected by fibrin(ogen) treatment.
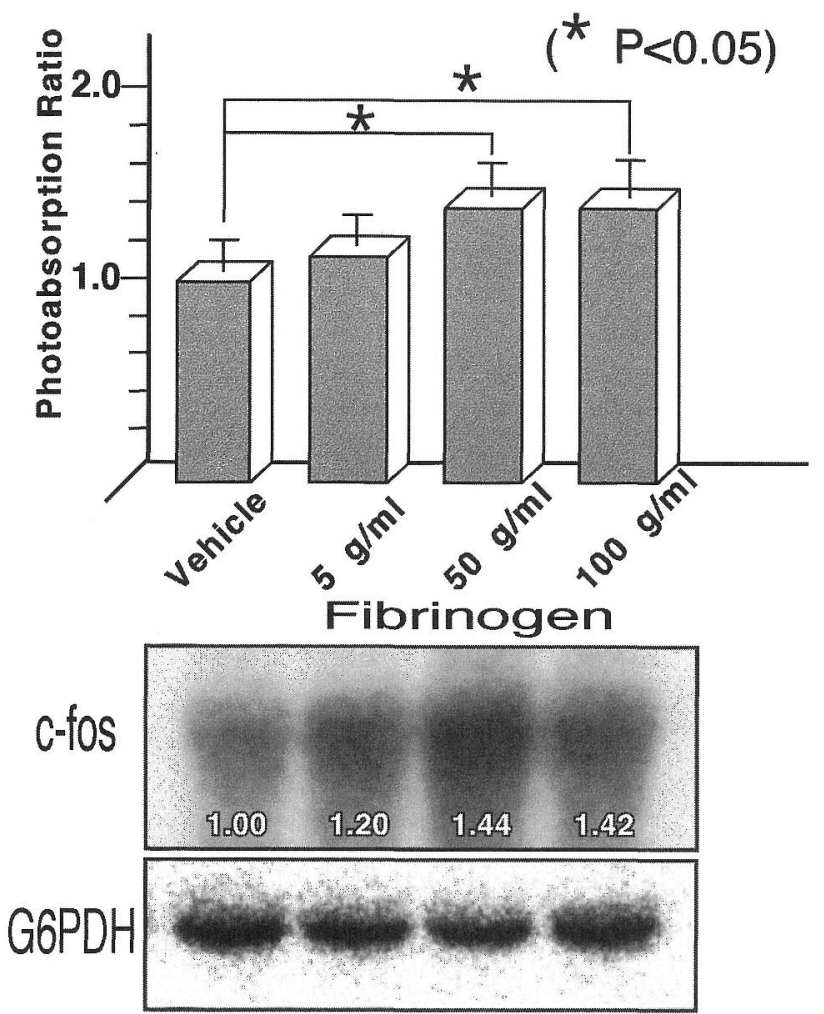

Fig. 6. Effect of fibrin(ogen) on cell proliferation. C3H10T1/2 cells were treated with vehicle, 5,50 or $100 \mu \mathrm{g} / \mathrm{ml}$ of fibrin(ogen). Cell numbers were assessed by photoabsorbance $(420 \mathrm{~nm})$ using the WST-1 assay system. An increase of up to $25 \%$ in cell numbers and c-fos expression was observed by fibrin(ogen) treatment. The relative optical densities to the control, standardized by G6PDH, are listed.

by ISH earlier than by immunohistochemistry [6]. Singlestranded antisense DNA probes synthesized by uni-directional PCR $[7,8]$ were used. To synthesize the singlestranded (either sense or antisense) DNA, a 'two-step PCR' instead of asymmetric PCR [14] was done: the first (conventional PCR) to yield a template double-stranded DNA, and the second (uni-directional PCR) for DIGlabeling with either sense or antisense primers.

Since the initial step of wound healing is triggered by serum substances leaked from blood vessels [11], the localization of the fibrin(ogen) in the bone fracture site was first checked by immunohistochemistry. Among the serum factors that promote wound healing, we especially focused on fibrin(ogen) because fibrin(ogen)-glue has already been applied in the medical field to support orthopedic surgery. As expected, in our present study, fibrin clots were abundant at the fracture site for two days (Fig. 1). At this stage of the hematoma, only a nominal amount of signals of bone matrix proteins expressed on mesenchymal cells at the fractured sites. The cells within the hematoma itself, on the other hand, did not express bone matrix proteins. Also in our previous study on the expression of BMPs [7], the cells within the hematoma did not express BMP. The role of the hematoma [10] in frac- 
ture healing, therefore, might be that of a container for the growth and/or differentiation factors leaked from blood vessels rather than a source for the mesenchymal cells. Indeed, on day 7 , close to the remnant fracture hematoma, the endochondral ossification site was found to contain mesenchymal/chondrocytic cells initially expressing strong signals of bone matrix proteins (Fig. 3B, C), and was, therefore, thought to be the major source of the mesenchymal cell lineage advancing fracture healing. Together with our previous study [7] showing mesenchymal cells proliferating adjacent to the fractured site express BMPs, increased expression of the bone matrix proteins was mediated through the autocrine and/or paracrine action of BMPs. Indeed in the in vitro studies, BMPs contribute to the proliferation and differentiation of chondrocytes [4, 15], and have also been reported to stimulate osteoblastic differentiation of cultured mesenchymal/stromal cells to express bone matrix proteins [19, 20].

In vitro treatment with fibrin(ogen), a major component of the fracture hematoma, was found to slightly promote proliferation of cultured mesenchymal cells (Fig. 6). To assess the direct effects of fibrin(ogen) on the osteoblastic differentiation of mesenchymal cells, the expression of bone matrix proteins and markers for osteoblastic phenotypes were analyzed by Northern blotting. Besides osteonectin and osteopontin, alkaline phosphatase and biglycan were selected as mid-phase and late-phase markers, respectively, of osteoblastic differentiation. As shown in Fig. 4, the steady-state level of osteonectin mRNA was increased by fibrin(ogen) treatment. The level of osteopontin mRNA was also increased by fibrin(ogen), albeit to a lesser degree than that of osteonectin. Fibrin(ogen), on the other hand, had little effect on the expression of alkaline phosphatase and biglycan genes (Fig. 5). This indicates that fibrin(ogen) alone is not sufficient to induce complete osteoblastic features. Since osteoblastic cells constantly express osteonectin during osteoblastic differentiation and start to express osteopontin at the early-mid phase of osteoblastic differentiation [5], our results indicated that fibrin(ogen) may be a contributing factor in initiating the differentiation of mesenchymal cells into the osteoblastic cell lineage.

In conclusion, our data suggest that the fibrin clot at the fracture site could be one of the factors that promote fracture healing at the early phase by regulating the differentiation of immature mesenchymal cells.

\section{Acknowledgments}

This work was supported in part by a Grant-in-Aid for Scientific Research from the Ministry of Education of Japan. The authors thank Ms. Atsumi Kodan, Ms. Izumi Iwamoto and Mr. Shuichi Matsumoto for their excellent technical assistance.

\section{References}

1. Arbes, H., Bosch, P., Lintner, F. and Salzer, M.: First clinical experience with heterologous cancellous bone grafting combined with the fibrin adhesive system (F.A.S.). Arch. Orthop. Trauma Surg. 98; 183-188, 1981.

2. Bostrom, M. P., Lane, J. M., Berberian, W. S., Missri, A. A., Tomin, E., Weiland, A., Doty, S. B., Glaser, D. and Rosen, V. M.: Immunolocalization and expression of bone morphogenetic protein 2 and 4 in fracture healing. J. Orthop. Res. 13; 357-367, 1995.

3. Dvorak, H.F., Harvey, V.S., Estrella, P., Brown, L. F., McDonagh, J. and Dvorak, A. M.: Fibrin containing gels induce angiogenesis. Implications for tumor stroma generation and wound healing. Lab. Invest. 57; 673-686, 1987.

4. Grimsrud, C. D., Romano, P. R., DeSouza, M. J., Reynolds, P. R., PUzas, J. E., Rosier, R. N. and O'Keefe, R. J.: BMP-6 commits chondrocytes to the hypertrophic phenotype. J. Bone Miner. Res. 12 (suppl. 1); S161, 1997.

5. Ibaraki, K., Termine, J. D., Whitson, S. W. and Young, M. F.: Bone matrix mRNA expression in differentiating fetal bovine osteoblasts. J. Bone Miner. Res. 7; 743-754, 1992.

6. Iwasaki, Y., Hara, Y., Koji, T., Shibata, Y., Nakane, P. K. and Kato, I.: Differential expression of IFN- $\gamma$, IL-4, IL-10, and IL-1 $\beta$ mRNAs in decalcified tissue sections of mouse lipopolysaccharide-induced periodontitis mandibles assessed by in situ hybridization. Histochem. Cell Biol. 109; 339-347, 1998.

7. Kitazawa, R., Kitazawa, S., Kashimoto, H. and Maeda, S.: Expression of bone morphogenetic proteins in fractured mouse bone tissue: in situ hybridization with polymerase chain reaction (PCR)-derived antisense DNA probe. Acta Histochem. Cytochem. 31; 231-236, 1998.

8. Kitazawa, S., Kitazawa, R. and Maeda, S.: In situ hybridization using polymerase chain reaction (PCR)-derived singlestranded DNA probe and S1 nuclease. Histochem. Cell Biol. 1998. (in press)

9. McKibbin, B.: The biology of fracture healing in long bones. Can. J. Surg. [Br] 60; 150-162, 1975.

10. Mizuno, K., Mineo, K., Tachibana, T., Sumi, M., Matsubara, T. and Hirohata, K.: The osteogenic potential of fracture haematoma. Subperitoneal and intramuscular transplantation of the haematoma. J. Bone Joint Surg. Br. 72; 822-829; 1990.

11. Nagy, J. A., Brown, L. F., Senger, D. R., Lanir, N., Van de Water, L., Dvorak, A. M. and Dvorak, H. F.: Pathogenesis of tumor stroma generation: a critical role for leaky blood vessels and fibrin deposition. Biochim. Biophys Acta 948; 305-326, 1989.

12. Nakase, T., Nomura, S., Yoshikawa, H., Hashimoto, J., Hirota, S., Kitamura, Y., Oikawa, S., Ono, K. and Takaoka, K.: Transient and localized expression of bone morphogenetic protein 4 messenger RNA during fracture healing. J. Bone Miner. Res. 9; 651-659, 1994.

13. Pohl, J., Bruhn, H. D. and Christophers, E.: Thrombin and fibrin-induced growth of fibroblasts: role in wound repair and thrombus organization. Klin. Wochenschr. 57; 273-277, 1979.

14. Scully, S. P., Joyce, M. E., Abidi, N. and Bolander, M. E.: The use of polymerase chain reaction generated nucleotide sequence as probes for hybridization. Mol. Cell Probes 4; 485-495, 1990.

15. Shukunami, C., Ohta, Y., Sakuda, M. and Hiraki, Y.: Sequential progression of the differentiation program by bone morphogenetic protein-2 in chondrogenic cell line ATDC5. Exp. Cell Res. 241; 1-11, 1998.

16. Simmons, D. J.: Fracture healing perspectives. Clin. Orthop. $208 ; 300-312,1986$. 
17. Smith, J. W., Ruggeri, Z. M., Kunicki, T. J. and Cheresh, D. A.: Interaction of integrins $\alpha \mathrm{v} \beta 3$ and glycoprotein IIb-IIIa with fibrin(ogen). Differential peptide recognition accounts for distinct binding sites. J. Biol. Chem. 265; 12267-12271, 1990.

18. Takaoka, K., Yoshikawa, H., Hashimoto, J., Miyamoto, S., Masuhara, K., Matsui, M. and Ono, K.: Purification and characterization of a bone-inducing protein from a murine osteosarcoma (Dunn type). Clin. Orthop. 292; 329-336, 1993.

19. Thies, R. S., Bauduy, M., Ashton, B. A., Kurtzberg, L., Wozney, J. M. and Rosen, V.: Recombinant human bone morphogenetic protein-2 induces osteoblastic differentiation in
W-20-17 stromal cells. Endocrinology 130; 1318-1324, 1992.

20. Yamaguchi, A., Katagiri, T., Ikeda, T., Wozney, J. M., Rosen, V., Wang, E. A., Kahn, A. J., Suda, T. and Yoshiki, S.: Recombinant human bone morphogenetic protein-2 stimulates osteoblastic maturation and inhibits myogenic differentiation in vitro. J. Cell Biol. 113; 681-687, 1991.

21. Yu, C. C., Dublin, E. A., Camplejohn, R. S. and Levison, D. A.: Optimization of immunohistochemical staining of proliferating cells in paraffin sections of breast carcinoma using antibodies to proliferating cell nuclear antigen and the Ki-67 antigen. Anal. Cell Pathol. 9; 45-52, 1995. 